\title{
Democracia y tecnologías digitales
}

\author{
Democracy and digital technologies \\ Democracia e tecnologias digitais
}

EDITORIAL

\section{Ruth S. Contreras Espinosa}

\author{
Universitat de Vic-Universitat Central de Catalunya \\ Profesora del Departamento de Comunicación. Editora de la revista Obra Digital. \\ ruth.contreras@uvic.cat \\ orcid.org/0000-0002-9699-9087
}

\section{Resumen:}

Las tecnologías de la información y la comunicación están moldeadas por la sociedad, pero también modificadas por las estructuras políticas. Y es precisamente por los desarrollos tecnológicos recientes, que se ha actualizado y estimulado el debate sobre el gran potencial democrático que tienen. La idea de una sociedad de la información ha servido para abrir el debate sobre los principios democráticos que deben estar presentes en la tecnología. De ahí la importancia de prestar atención al tema. Vincular tecnologías y democracia implica hablar de un amplio abanico de escenarios en los que interactúan diferentes usuarios, contenidos, y diversos elementos.

\section{PALABRAS CLAVE}

Democracia, Participación, Tecnologías de la información y la comunicación, Tecnologia digital.

\section{Abstract:}

Information and communication technologies are shaped by society but also modified by political structures and it is precisely because of recent technological developments that the debate about their great democratic potential has been updated and stimulated. The idea of an information society has served to open the debate on the democratic principles that should be present in technology. Hence the importance of paying attention to the subject. Linking technologies and democracy implies 
talking about a wide range of scenarios in which different users, content, and various elements interact.

\section{KEYWORDS}

Democracy, Participation, Information and Communication Technology, Digital Technology.

\section{Resumo}

As tecnologias de informação e comunicação são moldadas pela sociedade, mas também modificadas pelas estruturas políticas. E é justamente por causa dos desenvolvimentos tecnológicos recentes que o debate sobre seu grande potencial democrático tem sido atualizado e estimulado. A ideia de uma sociedade da informação tem servido para abrir o debate sobre os princípios democráticos que devem estar presentes na tecnologia. Daí a importância de se prestar atenção ao assunto. Ligar tecnologias e democracia implica falar sobre uma ampla gama de cenários nos quais diferentes usuários, conteúdos e vários elementos interagem.

\section{PALABRAS-CHAVE}

Democracia, Participação, Tecnologias de Informação e Comunicação, Tecnologia Digital.
A diferencia de las tecnologías de alto riesgo, las tecnologías de la información y la comunicación son una tecnología de red sistémica que genera factores de apoyo a la democracia (Barber 2002). Todas aquellas innovaciones que involucran a redes y servicios han ampliado sus capacidades y han reducido el costo de transmitir voz, video, texto, datos e imágenes en tiempo real. Incluso, han demostrado de manera convincente todo el potencial para poder remodelar la organización de la sociedad. Principalmente, porque las TIC son vistas en sí mismas como terrenos en disputa, sitios de lucha discursiva, como el foco del activismo (Dahlberg, 2011) y como espacios educativos.

La tecnología es moldeada por la sociedad, pero también es modificada por las estructuras políticas (Werle 2000). Y es precisamente por los desarrollos tecnológicos recientes, que se ha actualizado y estimulado el debate sobre el gran potencial democrático que tienen las tecnologías de la información y la comunicación (TIC). La idea de una sociedad de la información también ha servido para abrir el debate sobre los principios democráticos que deben estar presentes en la tecnología. De ahí la importancia de prestar atención al tema. Se reconoce la interrelación entre la sociedad y la tecnología y en la que los procesos de cambio económicos, sociales y culturales interactúan con los cambios tecnológicos. Estos cambios conducen a diferentes tipos de sociedad de la información, consideradas democráticas. Podría decirse que la calidad democrática depende de cómo se apliquen las TIC, porque la tecnología puede permitir que las personas obtengan la información que necesitan para examinar las posiciones y problemas políticos en competencia, y proporcionan los medios para su registro y posterior agregación, como 'opinión pública', de sus elecciones a través de voto electrónico, sistemas de retroalimentación web, peticiones, correo electrónico, encuestas en línea, etc. (Dahlberg, 2011) o puede permitir el acceso a servicios diseñados para mejorar el acceso de los discapacitados u otras minorías desfavore- 
cidas, a la educación. La calidad democrática puede llegar a ser incluso el resultado de un accidente histórico. Por ejemplo, la evolución de Internet y de los protocolos TCP / IP en los que se basa la red de redes. En sus inicios no existía un plan que guiara el desarrollo de la red con la intención de obtener dividendos. Acabó siendo un accidente, porque se hablaba de un dividendo democrático de naturaleza de dominio público.

De acuerdo con los autores Catinat y Vedel (2000), todo depende de cómo las autoridades públicas hagan uso de las TIC. La tecnología es social tanto en sus orígenes como en sus efectos (Mackay 1995), y no lo es solo en el marco de su uso, sino incluso en el marco dentro del cual se diseña la tecnología, lo que les hace jugar un papel crucial en dar forma a la calidad democrática de las TIC.

La importancia social y política de las TIC es notable sin duda. En primer lugar, el alcance y la amplitud de los sistemas de TIC, donde se puede considerar a las infraestructuras de información y comunicación y su penetración en la sociedad de una manera análoga. La combinación del alcance, la amplitud y el grado de penetración de dichos sistemas subraya la importancia de su calidad democrática. Estas características pueden ser más o menos compatibles con los valores y estructuras de la democracia. En segundo lugar, está relacionada con la naturaleza de red de las TIC. Unas de las propiedades genéricas de una tecnología de red es la interdependencia y la complementariedad. Y según el diseño creado para los usuarios, tienen efectos que no se limitan a solo un individuo, sino que también afectan a todos los usuarios de esas tecnologías (Iversen et al., 2004). Por tanto, todas las opciones relativas a su diseño y uso pueden evaluarse desde el punto de vista de sus ramificaciones democráticas.

La importancia de la tecnología de la información y las comunicaciones para una sociedad democrática se ha apoyado además en expectativas vinculadas al crecimiento y desarrollo de Internet. Se considera que la web facilita la democracia digital, la democracia en línea, y que gracias a ella interactuamos en distintos contextos (globales y locales), con diversos impactos (sociales, políticos, personales) y con diferentes objetivos (positivos y negativos). Pero las TIC por sí mismas no fortalecen a la democracia. Sus efectos dependen en gran parte de los fines para los que se utilizan las tecnologías y están determinados principalmente por el diseño de las tecnologías que se utilizan, que pueden ser compatibles con los principios generales de la gobernabilidad democrática (igualdad, acceso, transparencia, rendición de cuentas, etc). El que una tecnología apoye o impida la democracia rara vez puede atribuirse directamente a los intereses y preferencias que dan forma al proceso de diseño.

La revista Obra Digital ha sentido la necesidad de atender a un área poco explorada que reúne dos temas importantes en nuestro día a día: las TIC y la democracia. Nuestro número 19, correspondiente a los meses de septiembre de 2020 a enero de 2021, se nutre de 6 artículos en el bloque del monográfico que se titula "Usos digitales para la promoción de experiencias democráticas" y que está coordinado por el Dr. Jordi Collet-Sabé y la Dra. 
Mar Beneyto-Seoane, ambos investigadores de la Universitat de Vic-Universitat Central de Catalunya. En los artículos de este número, los autores establecen un cuerpo holístico de conocimiento que nos invita a reflexionar y profundizar sobre los diferentes impactos sociales y educativos que se han generado en el proceso de interacción entre las tecnologías y la democracia. Como expertos en el tema, los autores están en una buena posición para describir el estado de la cuestión, reflexionar sobre los distintos procesos que se producen en diferentes entornos virtuales, su vinculación con la democracia y el análisis de los impactos sociales y educativos que puede generarse en estos espacios. Vincular tecnologías y democracia implica hablar de un amplio abanico de escenarios en los que interactúan diferentes usuarios, contenidos, y diversos elementos.
No quiero cerrar esta presentación, sin invitar a nuestros queridos lectores a consultar además los dos artículos de miscelánea que conforman nuestro número diecinueve. El primero de ellos titulado el "NETFLIX como productor audiovisual: Una radiografía de la coproducción de ficciones seriadas" y el segundo de ellos "Contextos de aprendizaje participativos en secundaria".

\section{Referencias}

Barber, B. R. (2002). The Ambiguous Effects of Digital Technology on Democracy in a Globalizing World. In Banse, G., Grunwald, A. \& Rader, M. (Eds.), Innovations for an e-Society. Challenges for Technology Assessment (pp.43-56). Edition sigma.

Catinat, M., \& Vedel, T. (2000). Public Policies for Digital Democracy. In Hacker K.L. \& Dijk J.V. (Eds.), Digital Democracy. Issues of Theory and Practice. (pp.184-208). Sage.

Dahlberg, L. (2011). Re-constructing digital democracy: An outline of four 'positions'. New Media \& Society, 13(6), 855-872. https://doi.org/10.1177/ 1461444810389569.

Iversen, E., Vedel, T., \& Werle, R. (2004). Standardization and the Democratic Design of Information and Communication Technology. Knowledge, Technology and Policy, 17(2), 104-126.

Werle, R. (2000). The Impact of Information Networks on the Structure of Political Systems. In Engel, C., Kenneth H. K. (Eds.), Understanding the Impact of Global Networks on Local Social, Political and Cultural Values. (pp.167-192). Nomos. 